\title{
Notating Deconstruction: What Can Ethnomusicological Transcription Learn from the Notational Practices of Contemporary Composers?
}

\author{
MATTHEW WARREN
}

\begin{abstract}
Drawing on Jacques Derrida's (1981) approach to deconstructing Platonic dichotomies, this article argues that any notational system is inherently structuring and should be subjected to deconstructive efforts. Further, my contention is that this deconstruction can be realized in how notation itself is used, in what I refer to as 'deconstructive notation'. This article looks at how notation has been used by composers to deconstruct the categories of Western staff notation, opening up the ways in which music is studied as an invitation to all those engaged in notating music to make room in their work for deconstructive notational play.
\end{abstract}

Here I start from the premiss that notation is both constructive and indicative of certain ways of thinking about music. Building on this, I argue that notation, as much as it can play this constructive role, can also play (and, indeed, has played) a deconstructive role by seeking to represent the unrepresented and to question the unquestioned. The perspective of this article is centred on the implications of the idea of notation's capacity to act deconstructively for transcription practices in ethnomusicology. However, by transgressing disciplinary boundaries in its subject matter, the article is intended more broadly as a provocation to all those engaged in notating music of any kind to explore notation, through a process of more playful and loosely structured practice, as a way of deconstructing systematized notational categories. This, as in Derrida's thought, serves the purpose of opening up disciplinary tenets to allow for more critical scholarship. First, I introduce the concept of deconstruction through Derrida's essay 'Plato's Pharmacy', illustrating the idea of deconstruction as an approach which seeks to destabilize engrained categories of

Email: matthew.j.warren@durham.ac.uk

I would like to thank the reviewers for $J R M A$, as well as Simon Mills, Susan Notess and John Snijders, for giving their time and insight to help me to develop this article; all those who listened to the paper from which it grew; and Durham University for funding my doctoral research. Finally, I would like to thank Andrew Killick for inspiring the chain of thought that led here.

(C) The Author(s), 2021. Published by Cambridge University Press on behalf of The Royal Musical Association. This is an Open Access article, distributed under the terms of the Creative Commons Attribution licence (https://creativecommons.org/licenses/by/4.0/), which permits unrestricted re-use, distribution, and reproduction in any medium, provided the original work is properly cited. 
thought. ${ }^{1}$ Secondly, I outline the ways in which any notation (as a system) establishes categories of musical thought. Thirdly, the main substance of the article explores and illustrates deconstructive uses of notation by composers which highlight (and undermine) the systematic assumptions of notational conventions, and relates these examples to transcription practices. These examples are what I refer to as 'deconstructive notations', and this article is an invitation to allow room in ethnomusicology (and music scholarship more generally) for looser, more playfully deconstructive approaches to notation.

\section{Derrida and deconstruction}

In Derrida's essay 'Plato's Pharmacy', he draws on a passage from Plato's Phaedrus in which Socrates illustrates the idea that speech is superior to writing by telling a story. Socrates relates that in Egypt writing was invented by Theuth, the Ibis-headed god who invented all sorts of artifices, including calculation and astronomy as well as (crucially) writing. Presenting his inventions to the god-king Thamus, Theuth claims that writing 'will make the Egyptians wiser and will improve their memories [...] My invention is a recipe (pharmakon) for both memory and wisdom.' In response, however, Thamus claims that it will have the opposite effect: the invention will produce forgetfulness, as 'it's not a remedy for memory, but for reminding' and gives only the semblance of wisdom since 'thanks to [writing], your pupils will be widely read without the benefit of a teacher's instruction'. ${ }^{2}$

In this story, then, Plato presents and evaluates a dichotomy between speech (as good, related to the internal memory, and living) and writing (as bad, related to the external sign, and dead). Theuth presents writing as a method of improving both wisdom and memory, but the god-king declares that it will achieve the very opposite of its intention by allowing the people to forsake both teachers and their internal memories. In this way, Plato's philosophy establishes and values concepts through clear-cut dichotomies.

In his treatment of this passage, Derrida takes a playfully deconstructive approach. In this period of his thinking, 'Deconstruction is a criticism of Platonism, which is defined by the belief that existence is structured in terms of oppositions (separate substances or forms) and that the oppositions are hierarchical, with one side of the opposition being more valuable than the other.' 3 Derrida's interest in this passage from Phaedrus concerns the way in which Plato forms a dichotomous relationship that attempts 'to master, to dominate by inserting its definition into simple, clear-cut oppositions: good and evil, inside and outside, true and false, essence and appearance'. ${ }^{4}$ Derrida directs himself towards the deconstruction of the argument by destabilizing the dichotomies that Plato has established. In order to do this, Derrida throws a wild card into Plato's

1 Jacques Derrida, 'Plato's Pharmacy', Dissemination, trans. Barbara Johnson (Chicago, IL: University of Chicago Press, 1981), 61-172.

2 Plato, Phaedrus, quoted in Derrida, 'Plato's Pharmacy', 75, 102.

3 Leonard Lawlor, 'Jacques Derrida', The Stanford Encyclopedia of Philosophy (2019), <https://plato. stanford.edu/archives/fall2019/entries/derrida/> (accessed 1 August 2019).

4 Derrida, 'Plato's Pharmacy', 103. 
dichotomy: he translates pharmakon as both a medicine and a poison. ${ }^{5}$ From the instability of this word, then, Derrida draws out the destabilization to the other dichotomies, crucially that of internal and external memory: 'The outside is already within the work of memory [...] Memory always, therefore, needs signs in order to recall the nonpresent, with which it is necessarily in relation [...] But what Plato dreams of is a memory with no sign.' ${ }^{6}$ This intentionally destabilizes the conventional reading of this passage and opens up the categorical hierarchy that Plato sets up, critiquing the logocentrism dominant in the history of Western philosophy.

Although it is a good illustration of this deconstructive approach, this is not unique to this particular work of Derrida's; the background to it lies in his early formulation of deconstructive thought in Of Grammatology and Writing and Difference, ${ }^{7}$ in which he considers the relationship between speech and writing, undermining the 'privilege of the phonè,${ }^{8}$ and in so doing highlights shortcomings perpetuated in the genealogy of philosophical history. In his deconstructive approach to writing, Derrida looks for the places where writing stands as a symbolic system that is not supplementary to speech, opening up the dominant hierarchical dichotomization. Deconstruction in a general sense, then, indicates an approach which highlights the contradictions and inconsistencies of clear-cut categorical thinking.

Often by looking in every category for traces of its opposite - the poison in the medicine, the external in the internal, and vice versa - Derridian deconstruction contains as its motif a kind of play that provokes rather than proves. It is this provocation which is sought here in terms of musical notation: how, for example, can notation highlight the social in the musical, the ephemeral in the permanent, the indeterminate in the determinate, the subjective in the objective and, ultimately, the contingent in the universal? Through its recurring motif of play, this kind of deconstruction can question and temper notationally constructed categories, facilitating an awareness of their arbitrariness and their potential to skew and distort scholarship. The approach does not seek to provide answers as Plato does, but prises open the argument, inviting the posing of new questions. By seeking to disassemble the categories of notation, the argument here is a response to Frank Kouwenhoven's plea for notation always to be 'a journey of broad discovery'?

\section{Ethnomusicology and notational systems}

This mode of thinking about notation is important in the recognition of the categories set up by any notational system. Even those explicitly designed by ethnomusicologists

5 Ibid., 70.

6 Ibid., 109.

7 Jacques Derrida, Of Grammatology, trans. Gayatri Chakravorty Spivak (Baltimore, MD: Johns Hopkins University Press, 1997); Derrida, Writing and Difference, trans. Alan Bass (Chicago, IL: University of Chicago Press, 1978).

8 Derrida, Of Grammatology, 7.

9 Frank Kouwenhoven, 'Transcribing "Time” in Chinese Non-Measured Songs', The World of Music, 47 (2005), 137-62 (p. 138). 
to be flexible (to circumvent the categorical assumptions that are still the 'chronic problem' of Western staff notation) ${ }^{10}$ still put in place certain categorical premisses that have the potential to structure the way in which music is understood. This can be seen in the case of Charles Seeger's and Andrew Killick's proposals for systems of universal descriptive notation, which themselves provide certain information in a particular graphical way whose rules constitute its structure. ${ }^{11}$ These notational methods - in Floris Schuiling's terms (drawing on those of Bruno Latour) - compose cultures of musical scholarship. ${ }^{12}$

However, the idea that notation is always in some way structuring of the ways in which we think about and study music is not new to ethnomusicology. The development of the discipline (which has had notation at the core of its practice) has been driven by a recognition that notation is necessarily incomplete, and that notations are abstractions which structure the music they seek to represent. Particularly with Western staff notation, the incompleteness of transcription and the partiality of notational categories has often been recognized. ${ }^{13}$ Seeger writes that transcription using Western staff notation 'can only be a conglomeration of structures part European, part non-European, connected by a movement 100 percent European. To such a riot of subjectivity it is presumptuous indeed to ascribe the designation "scientific".'14 Similarly, Robert Garfias writes that the 'standard western notation system tends to reinforce those aspects of the sound pattern which are compatible with our own notation traditions and in varying degrees to distort or omit others' ${ }^{15}$

The history of transcription has, therefore, been one of overcoming the distortion of music by the categories of notational systems born of 'colonial acquisitiveness' in which notation took on an aspect of proselytization under the guise of the enlightenment's dream of objective documentation. ${ }^{16}$ Innovations in ethnomusicological transcription have constituted acts which deconstructed the categories that had previously been applied as the definitive notational system of music. Just as phonetic writing, for Derrida, 'impos[ed] its laws upon the cultural areas that had escaped it', ${ }^{17}$ in music the categories of notation forced divergence to fit into their structures. Practices which

10 Mantle Hood, The Ethnomusicologist (New York: McGraw-Hill, 1971), 85.

11 Charles Seeger, 'Toward a Universal Music Sound-Writing for Musicology', Journal of the International Folk Music Council, 9 (1957), 63-6; Andrew Killick, 'Global Notation' (2019), <globalnotation.org.uk> (accessed 1 January 2020).

12 Floris Schuiling, 'Notation Cultures: Towards an Ethnomusicology of Notation', Journal of the Royal Musical Association, 144 (2019), 429-58 (p. 457).

13 Charles Seeger, 'Prescriptive and Descriptive Music-Writing', Musical Quarterly, 44 (1958), 184-95 (p. 184); Hood, The Ethnomusicologist, 82-3; Ter Ellingson, 'Transcription', Ethnomusicology: An Introduction, ed. Helen Myers (Basingstoke, 1992), 110-52; Kouwenhoven, 'Transcribing "Time" in Chinese Non-Measured Songs', 142; Jason Stanyek, 'Forum on Transcription', TwentiethCentury Music, 11 (2014), 101-61 (p. 101); Bruno Nettl, The Study of Ethnomusicology: ThirtyThree Discussions (Urbana, IL: University of Illinois Press, 2015).

14 Seeger, 'Prescriptive and Descriptive Music-Writing', 187.

15 In Nicholas England, Robert Garfias, Mieczyslaw Kolinski, George List, Willard Rhodes and Charles Seeger, 'Symposium on Transcription and Analysis', Ethnomusicology, 8 (1964), 223-77 (p. 233).

16 Ellingson, 'Transcription', 110.

17 Derrida, Of Grammatology, 10. 
were deconstructed in the course of the development of ethnomusicological transcription institutionalized patterns of thought that considered everything that did not fit to be 'accidental mistakes' and took 'the liberty of making alterations which they deemed improvements' ${ }^{18}$ This history, then, has been engaged with the structuring limitations of notation systems and has relied on critiquing accepted methods of notation to achieve its ends. It has repeatedly questioned the universal applicability of notational systems in order to keep 'ethnocentric prejudice' in check. ${ }^{19}$

However, even those practices which seem the least subjectively mediated have been called into question in this way. The construction of the dichotomy between mechanical transcription and the human ear has been formed into its own dialectic. ${ }^{20} \mathrm{With}$ the ready availability of both video and audio recording and playback, the need for transcription has come into question and its ubiquity in ethnomusicological writing has waned somewhat. ${ }^{21}$ In response to the critiques raised as a result of these developments, transcription has found its defence in the very subjectivity that is the source of the criticism: a person 'will perceive and transcribe music as culture, or cultural music', Marin Marian-Bălaşa argues, whereas 'computers render sonorous physicality, sheer acoustics, that which has only partially to do with culturally constructed music. This is why aural transcription is, more often than not, irreplaceable by computer sonograms and spectrum visualizations.' 22 The interaction of this dialectic is also clearly seen in debates in ethology over the merits of notating birdsong, where in a search for objectivity the discipline has often turned to mechanical transcriptions such as sonograms, but has still had to contend with the human manipulation and interpretation inherent in the process. ${ }^{23}$ Similarly, with systems of automatic transcription, which had the appeal of the universal for Seeger, ${ }^{24}$ as well as audio and video recording, the incompleteness and partiality of the mechanical system is ever-present. This is something highlighted by the moves in ethnographic filmmaking towards a more explicit emphasis being placed on the presence and partiality of the film-maker. ${ }^{25}$

\section{Constructive notation}

In considering the constructive aspect of notation, it is helpful to think of notation as one possible visualization of data, somewhat like drawing a graph to represent statistics. Bruno Nettl hints at this in his identification of Alan Lomax's cantometrics as a 'kind of

18 Carl Engel, quoted in Ellingson, 'Transcription', 116.

19 Hood, The Ethnomusicologist, 87.

20 Marin Marian-Bălaşa, 'Who Actually Needs Transcription? Notes on the Modern Rise of a Method and the Postmodern Fall of an Ideology', The World of Music, 47 (2005), 5-29 (p. 15).

21 Ibid., 5.

22 Ibid., 6 .

23 David Rothenberg, quoted in Stanyek, 'Forum on Transcription', 139.

24 Seeger, 'Toward a Universal Music Sound-Writing', 66.

25 See, for instance, Sarah Pink, Doing Visual Ethnography (Los Angeles, CA: SAGE, 2013), and Lorenzo Ferrarini, 'Enactive Filmmaking: Rethinking Ethnographic Cinema in the First Person', Visual Anthropology Review, 33 (2017), 130-40. 
transcription' ${ }^{26}$ The cantometric project involved devising categories of description for singing which could provide cross-culturally comparable data. Categories in the cantometric system included register, tempo, volume, repetitions, blend and group organization. ${ }^{27}$ Lomax, therefore, was not transcribing in the immediately recognizable sense of using 'notation that distinguishes temporal segments in a piece, one phrase from another, one note from the next', ${ }^{28}$ but still presented data which were set down to be interpreted. In this light, a conventional score in Western staff notation can be seen as a graph, or a series of graphs, showing discrete pitch degrees on the vertical axis and time units on the horizontal. This is even easier to see in transcriptions which more clearly resemble graphs - such as Seeger's melograph transcriptions or time-unit box systems $^{29}$ - or in musicological analyses where time is detached from its normal beat divisions, or even in some of the graph-like scores used by composers such as Morton Feldman. ${ }^{30}$

These examples, although they have different ends and originate in different disciplines, all present two categories as essential to the idea of music: pitch and time. All else, in this system, is secondary and tacitly assumed to be understood by the reader in the same way as by the notator. This leaves an idea of any musical notation system as prioritizing certain features in the perception of music and, indeed, in the understanding of what music is. This is what Philip V. Bohlman meant when he commented: 'Probably no form of essentializing music is as widespread as notation.' 31 The privileging of certain features in assumptions of what it means to notate music throws into relief those aspects which are tacitly assumed to be part of the music. That is to say, the notation does not specify those things which are perceived as so universal, so selfevident, that the notator need not notate them but may rely instead on an assumption of shared cultural literacy. Ethnomusicologists are often extremely interested in musical aspects which are generally accepted in a community and are therefore sources of common parlance, cohesion and community building. In many cases, this might be even more important to the study than those aspects that vary from work to work and from performance to performance. Notation depicts those aspects of the music which deviate from a norm, thereby carrying the invisible implication of that norm. To understand the music, then, an ethnomusicologist would have to read between the lines in notation and ask, 'What is so prevalent as to be not worth notating?' In this way, the categories of notations do not portray those aspects of the music that might be most significant - that is, those features which are so deeply embedded in the practice that they do not merit being notated. Notation specifies what is understood to be significant

\footnotetext{
26 Nettl, The Study of Ethnomusicology, 77.

27 Stephen Blum, 'Analysis of Musical Style', Ethnomusicology: An Introduction, ed. Helen Myers (London: Macmillan, 1992), 165-217.

28 Nettl, The Study of Ethnomusicology, 77.

29 Seeger, 'Prescriptive and Descriptive Music-Writing'; Gerd Grupe, 'Notating African Music: Issues and Concepts', The World of Music, 47 (2005), 87-103 (p. 96).

30 David Cline, The Graph Music of Morton Feldman (Cambridge: Cambridge University Press, 2016).

31 Philip V. Bohlman, 'Musicology as a Political Act', Journal of Musicology, 11 (1993), 411-36 (p. 420; emphasis original).
} 
musically within the categories of what is written, shows what the musical assumptions are through what is not written, and defines what is music at all by the sound's ability to be categorized on its terms. So it is that, through the categories of notation, as by the very act of notation, 'open narratives and plain theory (usually focusing upon technicalities) can cover hidden narratives of an ideological nature'. ${ }^{32}$ Wim van der Meer addresses this similarly forcefully:

Ethnomusicologists have used a most rigorous method for objectifying, essentializing and appropriating music of the 'other'. First by recording it [...] then by transcribing the recording and, in the process, reducing and distorting the music so as to adapt it to Western categories of musical thought. ${ }^{33}$

In this way, without denying the history of deconstructive notational work discussed above, it should be acknowledged that notation can provide a means by which scholars can socially classify music (and thus people) 'because it is carried out in the guise of acts of academic classification'. ${ }^{34}$ So it is that this tool of 'plain theory' can carry with it the kind of domination that Bohlman warns of when he writes that notation 'appeals to the colonizer and the colonized because it seemingly can underscore the integrity of another musical system by establishing its relation to the Western symbolic system'. 35

When faced with a proposal for a universal notation system, its universality might well appeal as a ready-to-use lingua franca with the promise of a standardized method of transcription. However, as Sylvia Smith writes: 'To standardize notation is to standardize patterns of thought and the parameters of creativity. ${ }^{36}$ As with Derrida and the categories that Plato constructs, a healthy scholarly discourse in ethnomusicology involves a continually renewed realization that any notation system puts in place categories that 'dominate ambiguity' and call for a response of deconstructive critique. This, for Derrida, is the measure of the 'quality and fecundity' of a discipline's discourse. ${ }^{37}$ Notational systems should be submitted to this deconstructive critique by highlighting ambiguities and tacit assumptions inherent in the system, making explicit the implicit and destabilizing the definite. While Schuiling proposes that this kind of reflection can be fostered by the relational study of notation cultures, ${ }^{38}$ the proposal here is that it can be enacted in how notation is used in scholarship itself. Deconstruction enacted through acts of notation is something which, as I will demonstrate, has also been a particular feature of the field of composition. By learning from this field, ethnomusicologists and others can draw on these practices in ethnomusicological transcription to employ a degree of notational deconstruction that

\footnotetext{
32 Marian-Bălaşa, 'Who Actually Needs Transcription?', 16.

33 Wim van der Meer, 'Visions of Hindustani Music', The World of Music, 47 (2005), 105-18 (p. 111$).$

34 Pierre Bourdieu, The State Nobility: Elite Schools in the Field of Power (Cambridge: Polity, 1996), 39 (emphasis original).

35 Bohlman, 'Musicology as a Political Act', 426.

36 Sylvia Smith, quoted in Thor Magnusson, Sonic Writing: Technologies of Material, Symbolic, and Signal Inscriptions (New York: Bloomsbury, 2019), 101.

37 Derrida, Writing and Difference, 356.

38 Schuiling, 'Notation Cultures', 457.
} 
qualifies and tempers the use of any notational system. I will illustrate what I mean by deconstruction with examples of what I see as deconstructive notation. ${ }^{39}$

\section{Deconstructive acts of notation}

Every notational system will subject music to the distortion of the categories it puts in place. Notation represents a certain set of data in a certain way, and so necessarily pours the fluidity and ephemerality of musical action into the mould of its categories. There is no such thing as a non-structuring system; it is inherent in the definition of a system. A system is that set of structural categories that seem so distorting in the analysis here. Therefore, while scholars act, they have to accept these distortions (they are, after all, the purchase that is needed for ideas to do their work), just as they accept the distortions of their own perspectives. As with egocentrism and ethnocentrism, however, the tempering force that counters the potential for distortion is awareness fostered by an impulse towards deconstruction of the accepted structures of notation. This impulse can be written and spoken, as it has often been, but it can also be found in acts of notation - that is, the thinking-through-doing that notating can constitute. Seeing the act of notation in this way (as a potential deconstructive provocation) presents the opportunity to use notation as a way of exploring and voicing deconstructive critiques of constructive notational systems that are used in transcription.

Ethnomusicological work can tend, despite the general disciplinary tendency towards deconstructing the centrality of any particular value system, to accept notation (particularly Western staff notation) as a neutral tool for documentation. This is not universally the case, but composers over the last century have been in an even more fractious relationship with Western staff notation, as they have sought to create music that focuses on different parameters or that undermines certain notions about the proper form of the musical act. Many have responded by devising various acts of what I will call here deconstructive notation. If, as above, constructive notation is considered to be those systems which put in place and maintain certain categories of presenting musical data, then deconstructive notations are those which undermine constructed systems, disrupt what in those systems is emphasized, and highlight what is omitted or diminished. ${ }^{40}$

39 This draws on my fieldwork with composers in England. The reader should note, however, that this should not be taken to mean that all examples are from composers who have been involved with my ethnographic research. Rather, it is indicative of the fact that my fieldwork has been generally formative for my thoughts on this subject, and this article is broadly informed by that context.

40 I should make clear that the binary distinction that I have set up - between constructive and deconstructive notations - is itself ripe for deconstruction: if a deconstructive notation is itself (however uniquely) a system with certain rules and referents, then it can be responsible for constructing categories and associated modes of thought. Similarly, if a constructive notation is unique in any sense, then it will contain the seeds of deconstruction. The deconstructive can be seen in the constructive and vice versa. The clarification to be drawn from this is that deconstruction is not a state of being, nor an inherent characteristic; and neither is construction: symbolic systems are neither deconstructive nor constructive, but rather they can act constructively or deconstructively in the process of the creation of meaning. The term 'deconstructive notation' therefore refers to a notation that is read as acting deconstructively in some way when contrasted with an ideal typical 
This counterposing of composition and transcription might, at first glance, seem to be flawed in that it brings into dialogue two categories of practice that have long been held as distinct - that is, descriptive and prescriptive notation. Seeger formulated the categories (respectively) as 'a blue-print of how a specific piece of music shall be made to sound' and 'a report of how a specific performance of it actually did sound'. ${ }^{41}$ Later, the description of conceptual notation was added to this mix (itself, in a certain way, a deconstructive idea). Ter Ellingson's definition of the concept is as a notation which is designed to 'furnish a graphic-acoustic definition of the essential concepts and logical principles of a musical system'. ${ }^{42}$ However, without entering here into a deconstruction of the categories of the prescriptive and the descriptive and how they relate to that of the conceptual (though this will be touched on later), the immediate proposition is this: by an encounter with notation that is conventionally kept apart by this boundary as well as disciplinary divisions, one is invited to read the descriptive in the prescriptive (and vice versa) and the conceptual at work in both. This allows the ambiguities in signification to form the basis of a play that detaches itself from the structures imposed by conventional definition.

Here, then, I present examples of notations that transgress the boundaries of conventional notation. The examples used are, of course, illustrative rather than comprehensive and draw on arguments made elsewhere, as well as experiences from my own ethnomusicological fieldwork with composers within academia in England. The examples are not intended as models for transcription systems for ethnomusicologists (although it may be that some find a use for them as such). ${ }^{43}$ Rather, they are intended to encourage music-notating scholars to engage more creatively and critically with the systems of transcription they use. For ethnomusicologists, this involves joining the 'few ethnomusicologists who unveil the dogmas and purposes behind the transcription issue revealing it either as hiding a fragile navigation between ideologies, or as providing the fundament for false or unnecessarily over-complicated analytical work'. ${ }^{44}$ These examples are notational acts that can aid in finding new directions in notation which move beyond the superficial tweaking of devices that can too readily be deployed unquestioningly; they can give rise to a deeper questioning of what notation is and does and of what it is assumed to be and do. I would also go further and contend that these examples and the modes of thinking that underlie them and

conventional Western staff notation. The term 'deconstructive notation' is used in order to avoid the potential confusion of the alternative: 'deconstructing notation'.

41 Seeger, 'Prescriptive and Descriptive Music-Writing', 184.

42 Ellingson, 'Transcription', 141.

43 Those looking to draw on specific techniques that have been used to solve notational problems in composition should know that others have approached this more directly. For an account of various notational innovations in the Western classical canon, see Richard Rastall, The Notation of Western Music: An Introduction, rev. edn (London: Travis \& Emery, 2010); and, for more comprehensive and practical guides to the extensions of notation in the twentieth century, see Howard Risatti, New Music Vocabulary: A Guide to Notational Signs for Contemporary Music (Urbana, IL: University of Illinois Press, 1975), and Kurt Stone, Music Notation in the Twentieth Century: A Practical Guidebook (New York: Norton, 1980). Alternatively, for a guide to Western staff notation and its conventions, see Elaine Gould, Behind Bars: The Definitive Guide to Music Notation (London: Faber Music, 2011).

Marian-Bălaşa, 'Who Actually Needs Transcription?', 15. 
emerge from their creation can even help to question fundamental ideas of musicological disciplines through notation itself.

\section{The parameters of notation}

As discussed above, deconstructive acts are those which destabilize assumptions, definitions and ideologies. They emphasize the unrecognized and legitimize the illegitimate. Notation consists of a set of categories awaiting (like any data representation) population. The categories selected by the path of history as being worth notating - as being constitutive of the work's identity - are not just significant to scholarship but also have 'real-world' implications. Nicholas Cook points to the example of a legal case in the US (further outlined by Anne Barron and Jason Toynbee) between the flautist James Newton and the Beastie Boys. ${ }^{45}$ A sample was used from Newton's recording of his solo flute composition Choir. The contention here was not over rights to the recording - this had been agreed with Newton's recording company but over the rights to the composition. In other words, the question was whether the composition, and not the recording sampled, was substantial and original enough to be an infringement of Newton's copyright. The judge ruled that a 'musical composition consists of rhythm, harmony and melody, and it is from these elements that originality is to be determined'. ${ }^{46}$ The passage in question consisted of a $\mathrm{C}$ played on the flute, while the performer sings $\mathrm{C}, \mathrm{Db}$ and then $\mathrm{C}$ over the top. In the categories that the judge laid out (rhythm, harmony and melody), the notes that constituted the 'composition' were not sufficiently original. However, Newton argued that 'his technique went beyond generic vocalization, and included overblowing the $\mathrm{C}$ note to produce "multiphonics", or multiple pitches', but 'the problem for the judge was that neither this nor [the use of portamento and a guttural timbre], claimed as unique, [was] notated in the score'. ${ }^{47}$ This case is a good illustration of the importance of categories of notation in understanding music: 'Notation is key here because it provides evidence of what is comprised in the work. This was an absolutely crucial point in Newton: the biggest problem for the flautist was that he had not made enough marks, not been exacting enough in his notation.' 48

Deconstructing these categories, therefore, is a real concern, and one that has greatly interested composers as the expansion of extended techniques has broadened their sonic palate and enabled them to focus on aspects of the sound not allowed by conventional notational categories. Because of the proliferation of these techniques in composition, the examples of adaptations (often on a small scale) where conventional notational devices fall short are far too numerous to exhaust. However, I will

\footnotetext{
45 Nicholas Cook, Beyond the Score: Music as Performance (New York: Oxford University Press, 2013), 14-15. Anne Barron, 'Introduction: Harmony or Dissonance? Copyright Concepts and Musical Practice', Social and Legal Studies, 15 (2006), 25-51; Jason Toynbee, 'Copyright, the Work and Phonographic Orality in Music', Social and Legal Studies, 15 (2006), 77-99.

46 Newton vs Diamond (2002), quoted in Toynbee, 'Copyright', 91.

47 Toynbee, 'Copyright', 91-2 (emphasis original).

48 Ibid., 93.
} 
highlight a couple of examples where some of the fundamental categories of notation have been radically redefined, implicitly undermining a certain notion of what parameters constitute the identity of the composition.

The first of these is from the work of Eric Egan, who describes his work as manipulating 'timbre and structure in particular ways':

[I] write pieces that have an element of physicality - a lot of movement [...] pieces where movement of the performer is a key aspect of the compositional material. There is the intersection between the body and the instrument, and the sound that comes out [...] is a result of the two. ${ }^{49}$

This focus on movement as a form of primary material is a key aspect of his music, but is something largely unapproachable for Western staff notation. He therefore develops notation which implicitly deconstructs the categories of conventional notation as concerned with specifying sonic results rather than procedural movements. Egan's solo cello work Hewn (see Figure 1) illustrates this. Here, bow position is shown by the location on the score of the black lines. The player follows the lines, with the thickness of the line corresponding to the bow pressure and speed: a thick line denotes heavy, slow bowing, while a thin line denotes light, fast bowing. Staff notation represents the string and fingerings.

This challenges the assumed primacy of the categories of time and pitch, which are conventionally allocated the visually dominant positions, being plotted along the horizontal and vertical axes respectively in Western staff notation. In their place, both axes are now devoted to the two-dimensional plotting of bow placement in space. In addition, the thickness of the line indicates bow pressure (that is, one could say, of depth of placement), and so the two dimensions become three and Egan has allowed himself to place the cellist's bow freely in space with an exactness and ability to gradate that with conventional notation he could achieve only with the utmost difficulty. He does not lose the elements of time and pitch, but rather foregrounds the essential (but usually tacit) element of physicality. Seen in the light of this deconstructive act of notation, conventional staff notation has an element of the absurd about it: the cellist cannot play without moving the bow, without placing it in this three-dimensional space, but Western staff notation gives no category for accurately specifying this (cumbersome and approximate sul tasto and sul ponticello markings aside). In the idea of deconstructive acts, then, subverting the traditional categories of time and pitch in favour of the neglected aspect of physical space highlights a certain sense of arbitrariness in the categories in conventional notation.

Taking this theme of deconstruction of the categories of notation in another direction, I turn to a striking deconstructive notation by the artist-printmaker Liz K. Miller. She has created a series of etchings which depict transcriptions in a notational system of her own devising. Her notation grew out of a curiosity about the repetitive structures of music, and in finding a way of communicating these structures to people

49 Eric Egan, interview with the author, 12 October 2018. 


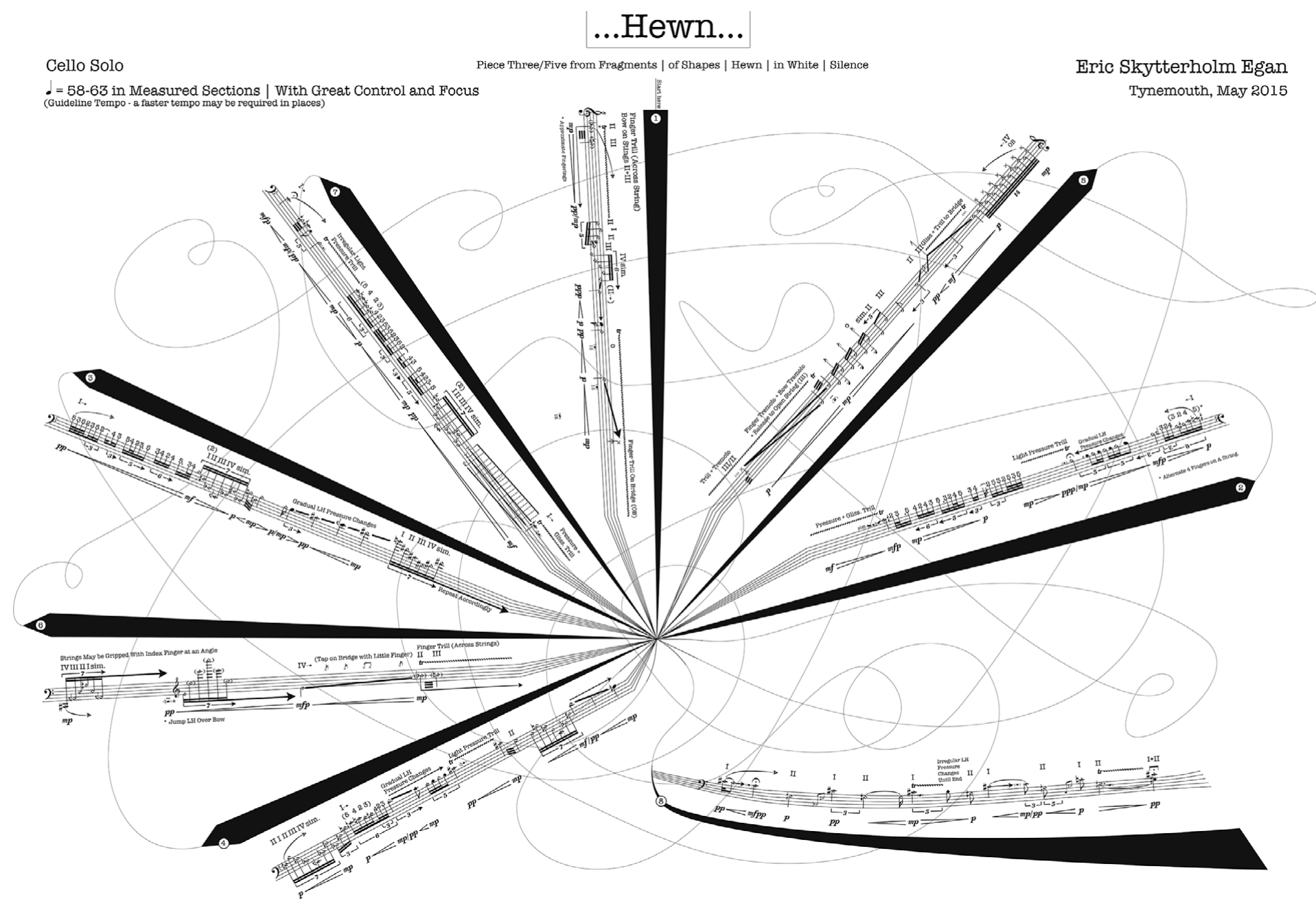

.$=58-63$ in Measured Sections $\mid$ With Great Control and Focus

...Hewn...

Tynemouth, May 2015

Figure 1 Eric Egan, Hewn. (C) 2015 Eric Egan, reproduced by permission of the composer. 


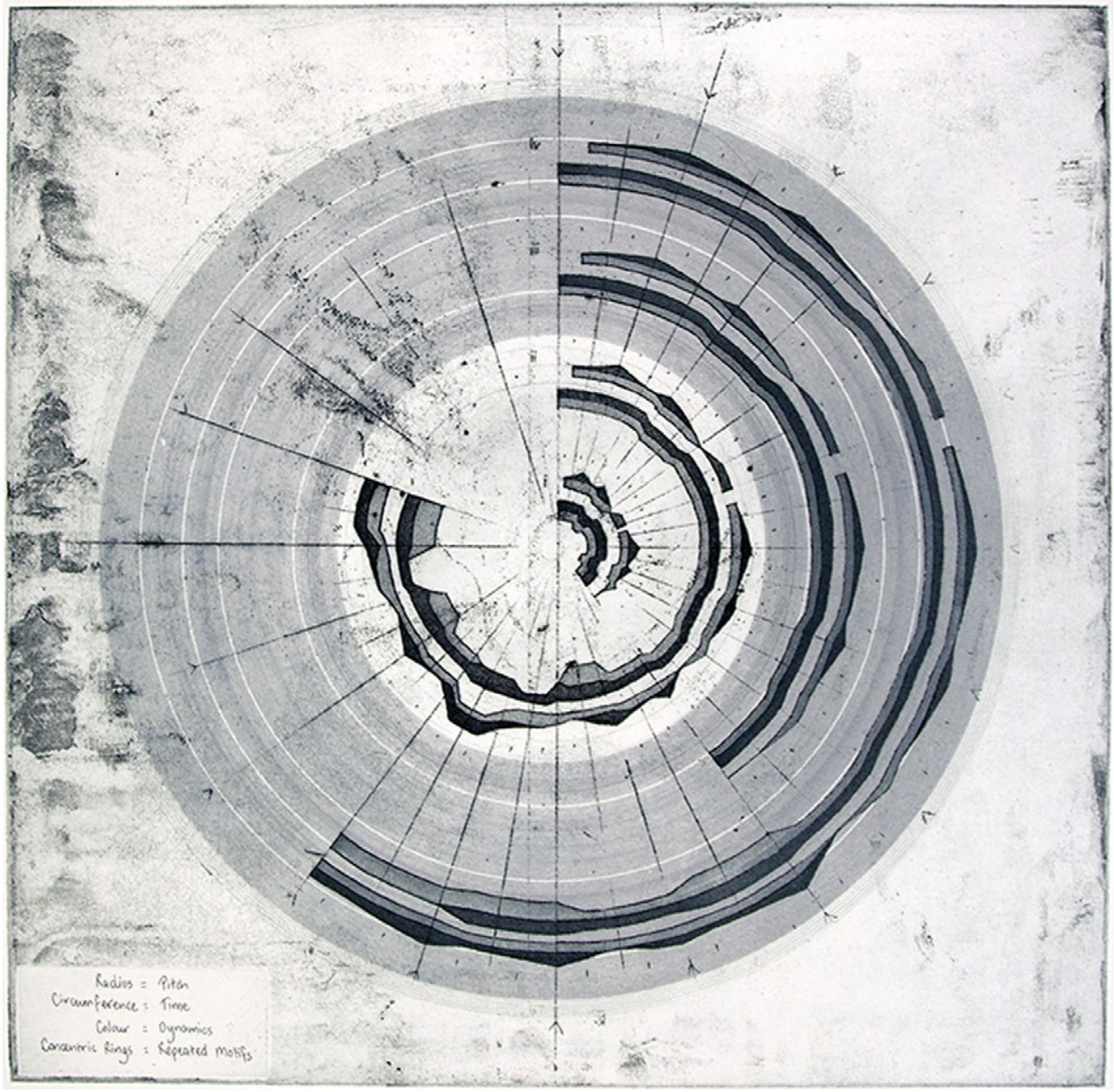

Figure 2 Liz K. Miller, Farewell on Vinyl. (C) 2014 Liz K. Miller, reproduced by permission of the artist.

who are not necessarily literate in Western staff notation and the accompanying analytical understandings that are required to gather the musical form. ${ }^{50}$

In Miller's Farewell on Vinyl (see Figure 2), time (or, more accurately, beat progression) is seen around the circumference of the circle; pitch corresponds to the radius; and repetitions are displayed in concentric partitions of the score. (Here there are four such partitions, progressing from the centre to the edge and each time beginning at ' 12 o'clock'.) In other words, each time the music - here, Peter Maxwell Davies's Farewell to Stromness - returns to the main theme, the notation returns to the top, starting the next concentric circle. This means that, unlike a conventional score,

$\overline{50}$ Personal communication, 9 January 2019. 
which, to bastardize Lewis Carroll, 'begins at the beginning, goes on until it comes to the end, then stops', the primary division of the score here is marked by the return to the particular theme, the start of which is written as the next circle out from the last.

The deconstructive aspect here is directed towards the temporal units which staff notation prioritizes. Here, the emphasis is shifted from notes, phrases and bars to the mapping of repetitive forms. This is reminiscent of the circular notation used by David Rycroft to illustrate the repetition of a polyphonic strophe. ${ }^{51}$ However, Miller and Rycroft achieve something slightly different: while Rycroft shows the music as having one dominant structural unit (the cycle), Miller's emphasis is on the unit of perceived repetition, even when it is non-identical in terms of the precise notes. She shifts the gaze to the repetition of contour above the discrete note. This comes back to the concept of notation as the malleable presentation of data, potentially provoking notators to consider what their notation is intended to present, and so what the best units for that purpose are. Certainly, in considering conceptual notation, the repetition of thematic material could easily be considered the primary category of a performer's conception of a piece. One study of a concert pianist, for example, showed a huge reliance on the formal structure of the music, with the pianist drawing on patterns of repetition and variation when learning and playing the piece. ${ }^{52}$ In light of the crucial role that repetition surely must play in conceptual transcription, the blind spots of conventional notation are highlighted by Miller's act of deconstructive notation.

\section{The relationship between notation and sound}

The assumption of a certain, definite relationship between notation and the sonic result has also come to be questioned through various acts of notation. Composers have variously created notations that undermine the transparency of intent that is characteristic of idealized versions of relationships between composers and performers, between performers and audiences, and between instruments and performers.

Stuart Paul Duncan presents an example of deconstructive notation in his discussion of the exact nature and function of complexity in Brian Ferneyhough's notation. ${ }^{53}$ Ferneyhough's notations are notorious for their 'intricately woven nested rhythmic strands, abrupt dynamic changes, and spectacular shifts in pitch', ${ }^{54}$ or (in the oversimplified view that Duncan sets out to contest) for the density of notes on the page. The notation is complex and exceptionally difficult to read, treading an ambiguous line between playable and unplayable. Duncan examines this uncertain performability, pointing out that the notation in Cassandra's Dream Song 'does not denote the ideal performance, as might be assumed. Traversing every disjunctive melodic fragment,

51 David Rycroft, 'Nguni Vocal Polyphony', Journal of the International Folk Music Council, 19 (1967), 88-103 (p. 91).

52 Roger Chaffin and Gabriela Imreh, "Pulling Teeth and Torture": Musical Memory and Problem Solving', Thinking and Reasoning, 3 (1997), 315-36.

53 Stuart Paul Duncan, 'Re-Complexifying the Function(s) of Notation in the Music of Brian Ferneyhough and the "New Complexity", Perspectives of New Music, 48 (2010), 136-72.

54 Ibid., 138. 
each with its own articulation and intricate rhythmic profile, is at times impossible.' 55 However, Duncan puts to one side the discussion of 'complexity' as equivalent to 'complication': that is, he avoids examining Ferneyhough's notation simply in terms of the quantity of information displayed. Instead, he argues,

The complexity of Ferneyhough's music derives not from the informational density of the score [...] - it is not that the litany of performative instructions, upon successful completion, transparently transmits the composer's prebuilt compositional system to the listener - but rather from a coalescence of the dialogues between composer and score, score and performance, and performance and reception.

'The notation does not present a single path,' he writes, 'but rather a labyrinth with multiple entrances and exits.' 56 Duncan sees the notation as critiquing the assumed idea of what it means to notate music, questioning 'the existence of a transparent relationship between composer, score, performer and listener' ${ }^{57}$ Ferneyhough's notation, therefore, is deconstructive in that, in this reading, it turns away from the ideal of the best realization of notation being a perfectly exact performance. Instead, it forces musicologists to engage with the performance as intentionally emerging from the 'problems and possibilities inherent in the notation-realization relationship', which are at the heart of the fundamental issues presented here with a notation system as a perfectible representational model. 58

While Ferneyhough used complexity to deconstruct the transparency/opacity dichotomy of the composer-performer-audience relationship, others have moved towards the simplifying of scores. Cornelius Cardew comments on the value of La Monte Young's $X$ (any integer) for Henry Flynt as lying in the appreciation of errors in the simple but strenuous performance task of repeating a uniform loud sound. He remarks: 'If the piece were performed by a machine this interest would disappear and with it the composition.' 59 The simplicity of Young's directive to play a sound repeatedly $\mathrm{X}$ number of times moves the score-performer relationship into a starkly audible place, as the audience hears every micro-variation (or 'error').

Others, too, have deliberately created notation which directs the performer's actions but deconstructs the transparency of the musical process: Scott McLaughlin, for example, writes music that 'tends to focus around the material agency of things and instruments'. ${ }^{60}$ His music often involves methods of instrument preparation that make the sonic output unpredictable, meaning 'that the player is constantly negotiating with the instrument about what comes out. So it's trying to move away from the paradigm of musicians controlling the instrument, making it do what they want.' 61 His notation,

\section{Ibid., 149.}

Ibid., 138, 163.

Ibid., 138-9.

58 Ferneyhough, quoted ibid., 150.

59 Cornelius Cardew, 'On the Role of the Instructions in the Interpretation of Indeterminate Music', Word Events: Perspectives on Verbal Notation, ed. John Lely and James Saunders (London: Continuum, 2012), 150-4 (p. 151).

60 Scott McLaughlin, interview with the author, 12 December 2018.

61 Ibid. 
therefore, is not only directed towards the critique of the composer's control over the composition, but also introduces another dimension into the composer-performeraudience relationship, namely the performer's connection to their instrument. As with Fernyhough, then, McLaughlin implicitly questions the transparency of the idealized conceptions of these communicative relationships. McLaughlin's central concern is: 'How do you compose a piece where you know that the instrument is going to be feeding back in a certain way to the player? [...] I'm more interested in writing pieces where the player has to respond to what the instrument does. ${ }^{62}$ Here, then, McLaughlin seeks to make explicit the implicit element of material agency that is inherent in the performance situation.

Although McLaughlin does not feel that he has yet settled on a way of notating this music, one solution he employs is to move towards relinquishing notational specificity and concentrating on notating performance process, often in combination with an unusual situational stress (such as instrumental preparation) to decrease the performer's level of control of the instrument and to foreground its material agency. Such an example would be this notation of his intra-actions for cello:

(1) continuously bow (as above) an open string until one stable partial or multiphonic dominates and the fundamental recedes or disappears completely.

(2) use double-stopping to smoothly and slowly crossfade (over several bow lengths), to a string adjacent to that used in (1), but aim for a partial with the same sounding pitch as was achieved in (1). If a stable partial is achieved that is the same pitch as (1) then goto [sic] (3), else goto (4).

(3) return (by slow double-stopped crossfade) to the string played in (1) and attempt to play the same partial as was achieved in (1). Simultaneously, detune one string that was not used in (1) or (2). If the same partial is achieved then goto (2), else goto (4).

(4) detune the string currently being played, then goto (1) without double-stopped crossfade. Begin process again with another string. ${ }^{63}$

McLaughlin refers to this as a 'prose score algorithm', ${ }^{64}$ replacing any form of graphic notation with text. While a graphic notation is bound to both prescriptive and descriptive signs, preordaining elements that would smother the material agency at the heart of his concept, this text treats both performer and instrument as acting and reacting agents, rather than as automatons devoted to producing and reproducing a blueprint.

This links with Egan's score (Figure 1). Egan conceives of movement not just as an element of the notation that is necessary in order to achieve his desired sound, but as primary material. In this conception the sonic result is derived from the intersection of movement and notated intention. Here, then, the foregrounding of the physicality of

62 McLaughlin, interview with the author, 12 December 2018.

63 (C) 2013 Scott McLaughlin, reproduced by permission of the composer. Score reproduced from Scott McLaughlin, 'intra-play: Notating for Contingent Materiality in Open-Form Works' (2018), 64 $<$ https://www.youtube.com/watch?v=qA_3mg7jwms\&feature=youtu.be> (accessed 15 July 2019). 
the performer's body (like the foregrounding of the instrument's physical agency in McLaughlin's work) undermines notational categories of intentional sounds as being of primary conceptual importance. One must read the score holistically as music that is dependent on a multivariate performance method - that is, as music in which intention is mediated by the physicality of the instrument and the performer's body: 'It's not this traditional sense that notes on the page produce sounds and they are then the fixed form.' ${ }^{65}$ This notation, then, deconstructs the assumed correspondence between representation and sound by highlighting the (usually unnotated) ambiguities of physical movement in the performance process.

This example invites a reconsideration of transcription in a way that is very directly relevant to musicological work. Thor Magnusson extends what one might formulate (by analogy with Derrida) as the musical 'text' to musical instruments, which 'contain music, theory, and culture'. ${ }^{66}$ As part of the 'text', the instrument not only is a passive subject but also has its part to play in the network of agencies that make up the social. Similarly, Cardew went on to remark of $X$ (any integer) for Henry Flynt: 'Truly this piece is gladiatorial; what the audience comes to witness is a rosy crucifixion.' ${ }^{67}$ For Cardew, then, the compositional structure is in the physical exertion of the performer in attempting the performance, just as for McLaughlin it is in that of the instrument. This could provoke questions as to how music can be transcribed in a way that highlights the physical interplay that determines a performance. This direction has, in fact, been explored, ${ }^{68}$ but could be taken still further. Such a transcription would be an extension of action notation, which Magnusson defines as being 'where the score consists of instructions to the performers as to how they should play their instrument or move their bodies', ${ }^{69}$ except that it would also involve notating how the instrument plays with the performer. Again, I am not putting forward any of these examples as proposed methods wholesale; rather, I am sharing them as an invitation to question where deconstructive thinking can take the practice of transcription.

These examples concentrate on creating circumstances under which the intentions of composer and performer are undermined by the instability of the situation. As prescriptive notation, these work well to deconstruct the primacy of intention so often ascribed to agents in the musical process. However, in the following examples notation engages with the idea of conscious choice in a way more like conceptual than prescriptive notation. Music, in all circumstances, is a result of choices made by all of the agents involved. Most obviously this applies to the performer and (where this labour is divided) to the composer, but it also applies to the audience. Performers all wield some freedom in their performance, and so are continually making decisions that

65 Egan, interview with the author, 12 October 2018.

66 Magnusson, Sonic Writing, 31.

67 Cardew, 'On the Role of the Instructions', 151.

68 Particularly in the use of tablature to illustrate playing technique (that is, the physical interaction between the instrument and the musician). See Roderic Knight, 'Towards a Notation and Tablature for the Kora and its Application to Other Instruments', African Music, 5 (1971), 23-36, and Grupe, 'Notating African Music', 99.

69 Magnusson, Sonic Writing, 99. 
are more or less prescribed by convention and/or notation; it therefore seems inescapable that a transcription would need to take account of these decision-making processes.

This, again, is something that has been used by composers. Explicit notation of choice has been a prevalent feature of the avant-garde movements of the latter half of the twentieth century. To choose one of many composers as an example, Cardew embraced complete freedom of choice in the interpretation of his graphic scores such as Treatise, but in other works, such as Schooltime Special, provided instructions for performance. In the latter piece, the performer reads a series of questions ('Do you want to sing a note? Yes? Sing one'; 'Do you want the music to stop now? Yes? Block your ears. No? Breathe on it to keep it glowing'; 'Do you need more questions? Yes? Make them up. No? Close your eyes and follow your inclination') and acts according to their answer. ${ }^{70}$ Other, less verbal/text-based approaches to notating choice can be seen, for example, in the work of Morton Feldman, Earl Brown and Christian Wolff. Notating choice in a modular way has been taken up as a method by a number of composers, perhaps most famously in Terry Riley's In $C$, but also by composers writing sets of parts which performers may choose to play in any combination, as in Christopher Fox's Everything You Need to Know and Egan's Through the Embers. In these examples, then, choices are more or less clearly delineated, and (crucially) the composition - that is, the identity of the work - maintains its integrity whatever the choices made by the performer.

Delineating boundaries is an essential part of the freedoms of music, just as it is of those of society. As a pharmakon, liberty exists only in its relationship to (and itself holds an element of ) restriction. This is particularly clear in the works of notation created by James Saunders. Many of his compositions engage with the act of notation as creating text instructions for a particular space. In Saunders's view, 'The intended result is not about getting people to do the thing I want. The intention in these pieces is to set up a situation where their personalities, idiosyncrasies, decisions, social capital becomes apparent. So they're quite open spaces. ${ }^{71}$ Saunders's pieces shape a decision-making space for performers and, occasionally, the audience, as in the piece descriptively entitled sometimes we do what you say, but occasionally we don't. In creating these spaces, he considers the importance of notating restrictions: 'A lot of the pieces aren't goalbased, so they just create an environment for decision-making [...] and of course there is decision-making there because I'm saying, "You can do these things, but not those things," and that creates the walls.' 72 Notationally, Saunders, like McLaughlin and Cardew, frequently uses text scores for this, outlining the rules of the piece but leaving the exact sounds made and the process of decision-making up to the social agents. This work, then, blurs the understanding of notation as concerned with what sound is made, but instead reframes intention as creating the space for certain social actions to be expressed through decision-making in relation to music. This deconstruction of what is

\footnotetext{
70 Cardew, cited in Word Events, ed. Lely and Saunders, 45-7.

71 James Saunders, interview with the author, 6 March 2019.

72 Ibid.
} 
important about the music - highlighting the parameters available to the decisionmakers, rather than what decisions are, or should be, made - is exactly aligned with the tenets of ethnomusicology; it sees music not as a specific sonic object, but as an aspect of social action, fraught with choice and all of the interwoven forces of social life. For the transcription of 'what people imagine or fantasize about [...] and what people culturally and socially construct', in Marian-Bălaşa's view, 'a mind endowed with multi-disciplinary cultural information, not to mention wisdom, is required' ${ }^{73}$ This being the case, Saunders's notations invite notators to consider what implications the inclusion or omission of the interwoven forces of the wider cultural text has for the choices that are made.

All of these examples give indications of how notation can be used to represent the kind of freedoms and limitations at play in any particular musical act. For Ellingson, the purpose of conceptual notation is to 'furnish a graphic-acoustic definition of the essential concepts and logical principles of a musical system' ${ }^{74}$ In which case, it would be a notation of possibility, and not just of actuality, representing the options available and the limits on those options as well as the choices made. If a transcription seeks to 'represent, precisely and in visually comprehensible form, musical factors essential to a piece and to the carriers of a music culture', ${ }^{75}$ then the examples presented here challenge ethnomusicologists to transcribe what the piece could be, while keeping its cultural identity as such, rather than simply the way in which a performer rendered it, or ought to have rendered it. Both the videographic notation of Regula Qureshi's study of qawwālī and (later) Martin Clayton's gestural transcriptions of khyāl depict audience activity and relate them to performers' musical decisions, making more explicit the social-contextual influence on the performance. ${ }^{76}$ In addition, Richard Widdess's method of collaborative approach to dhrupad transcription approaches the question of the frameworks for the decision-making of the performer. ${ }^{77}$ However, the examples presented above could provoke transcription to go further, making explicit those versions that the researcher (perhaps through reflection on multiple encounters with a situation) formulates as alternatives to what in fact happened.

\section{Living notation}

Plato (at least in Derrida's reading) aligns the qualities of being living and being dead with those of speech and writing respectively. In Western classical music's history, however, the score, far from suffering from lack of life, became valued in much scholarship above performance itself. This value derives from the idea of a composer

Marian-Bălaşa, 'Who Actually Needs Transcription?', 23.

Ellingson, 'Transcription', 141.

Erich Stockmann, quoted in Ellingson, 'Transcription', 142.

76 Regula Qureshi, Sufi Music of India and Pakistan: Sound, Context and Meaning in Qawwali (Cambridge: Cambridge University Press, 1986), chapter 6; Martin Clayton, 'Time, Gesture and Attention in a "Khyāl" Performance', Asian Music, 38 (2007), 71-96.

77 Richard Widdess, 'Involving the Performers in Transcription and Analysis: A Collaborative Approach to Dhrupad', Ethnomusicology, 38 (1994), 59-79. 
as a quasi-divine individual whom the performer is responsible for representing as faithfully as possible. ${ }^{78}$ 'Treating the score as divine law', the audience is then dutybound to try to interpret the meaning which the composer has encoded in the work. ${ }^{79}$ However, Cook argues that the pervasive idea of music as the score goes further than this; it is not simply that the composer is authoritative, but that the notation itself is the method by which one should create the form of music and that, 'The performer's role is at best to transcribe the work from the domain of the abstract to that of the concrete.' 80 He writes: 'The idea that composition proper proceeds through the exercise of reason, rather than through experimentation with instrument in hand, still survives in conservative critical circles. And in this context, the exercise of reason corresponds to the manipulation of notation.' ${ }^{81} \mathrm{He}$ roots this idealizing of the formal properties given to notation in a Platonic conception where music is 'an abstract and enduring entity that is reflected in notation, with the notation itself being reflected in the singing. ${ }^{82}$ In this school of thought, then, this Platonic epistemology actually inverts Plato's evaluation of writing in Phaedrus, placing the text as the proper, rational form of composition, which is most purely linked with the arrangement of forms and cannot be improved by performance.

In the examples discussed above, notation has been continually seen as static and fixed: the examples have had varying levels of specificity towards approaching different ways of deconstructing the interactions of the musical process, but they have all been fixed scores. The next examples, however, highlight the ways in which the stasis of a notation - the degree to which a work can be seen in a definitive representation - have been deconstructed. These examples are implicit critiques of the common idea of there being a real, authoritative (urtext) score.

First, I look at the notational practices of another composer, Michael Baldwin, whose work has repeatedly engaged with the notion of ephemerality. A key assumption in the common conception of notation is its permanence. In fact, this is important to Bohlman's argument that musicology makes static that which is not so. ${ }^{83}$ However, in Baldwin's notation of Ephemera 6: Window Shopping, the static nature of notation is questioned with dynamic scores which change and develop through processes of distortion, degradation and obscuration (see Figure 3). Here, the reader moves the window from place to place on the score, smudging and erasing parts of the notation as they go. This idea is a particular fascination of Baldwin's; he is interested in the notion of a score having a lifetime that, in reading it, one might be destroying or certainly changing. Indeed, in any discussion of notation, it seems inescapable that the starting

\footnotetext{
78 Bruno Nettl, Heartland Excursions: Ethnomusicological Reflections on Schools of Music (Urbana, IL: University of Illinois Press, 1995); Daniel Leech-Wilkinson, 'Compositions, Scores, Performances, Meanings', Music Theory Online, 18 (2012), <https://mtosmt.org/issues/mto.12.18.1/mto.12.18.1. leech-wilkinson.php> (accessed 2 February 2021).

79 Leech-Wilkinson, 'Compositions, Scores, Performances, Meanings', 1.2.

80 Cook, Beyond the Score, 13.

81 Ibid., 16.

82 Ibid., 11.

83 Bohlman, 'Musicology as a Political Act'.
} 


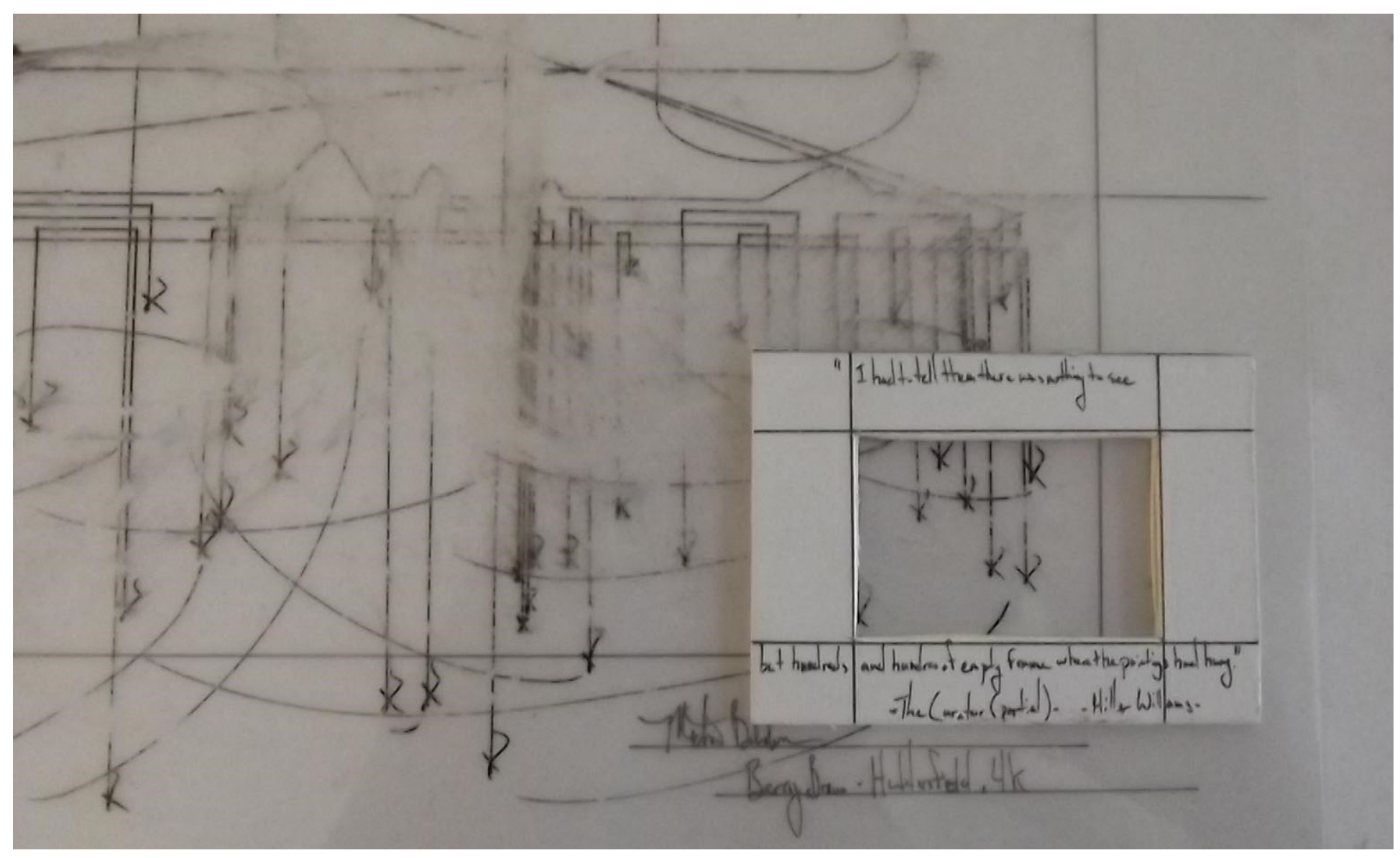

Figure 3 Excerpt/moment from Michael Baldwin, Ephemera 6: Window Shopping. (C) 2012 Michael Baldwin, reproduced by permission of the composer. 


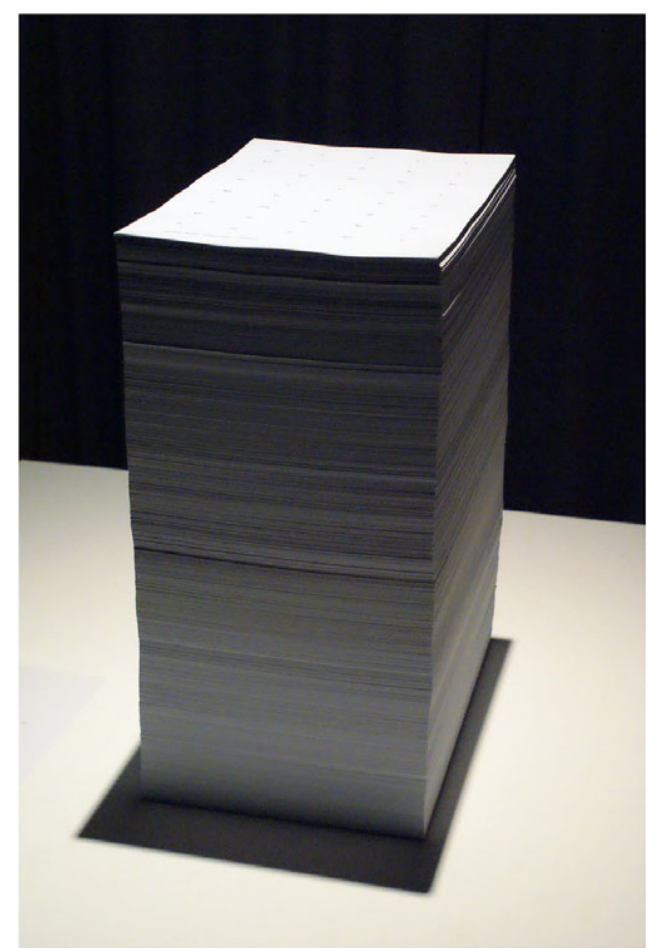

Figure 4 From Manfred Werder, stück 1998. (C) 2001 Manfred Werder, reproduced by permission of the composer.

tenet is some element of stasis, that the notation makes fixed what is transient, and that this is its value.

In another example, the lifetime of Manfred Werder's stück 1998 is restricted to its first performance. The 4,000-page-long score (see Figure 4) - representing just over 533 hours of music - is performed sectionally, in order, with every performance being of the next unperformed pages in the work. ${ }^{84}$ This resembles Baldwin's Ephemera 6, the performance of which was completed once all of the notation was erased. These ephemeral scores, therefore, deconstruct the dichotomous conception of scores as static and reproducible (in Plato's terms, 'dead'), as opposed to performance as ephemeral and unique ('living'), and with it the very notion of what constitutes a piece at all. In terms of ethnomusicological transcription, it undermines the 'illusion that a song, once put down on paper, is conquered, possessed, tamed, domesticated, subjected, and mastered'. 85

Baldwin also plays with the notion of erasure. In conventional notation, there is that which is written and that which is not - a dichotomy unbroken. Here, however, the uncertainty over what is notated and what is not is emphasized by the erasure and

84 Manfred Werder, stück 1998 (2018), <http://stuck1998.blogspot.com/> (accessed 17 July 2019).

85 Marian-Bălaşa, 'Who Actually Needs Transcription?', 17. 
distortion of the staff notation. In another excerpt from Ephemera 6, this was emphasized by the instruction to 'play everything'. The reader of the score, then, has their normal categories of notated and unnotated - written and erased - deconstructed in trying to make out the score (in a way reminiscent of Derrida writing 'under erasure', where the text is written and legible, but crossed out). ${ }^{86}$ In this instance, the ephemerality which Baldwin explores can be directly linked to Derrida's attempt to blur the categories of living and dead, with the scores evolving in just the way that Plato lauds the virtue of language as 'living, animate speech' as opposed to writing, which 'would rightly be called a kind of phantasm' preserved in a deathly, immortal stasis. ${ }^{87}$

To take this further, some composers have worked to create scores that exist only in oral transmission. Luke Nickel is one such composer, creating what he refers to as 'living scores'. These are scores that are created and transmitted orally, rather than graphically. Nickel's use of the term 'living score' refers to any 'contexts in which all compositional instructions are transmitted, rather than fixed'. ${ }^{88}$ In this sense, he still engages in the dichotomization which I am here seeking to deconstruct - that is, that the spoken is living, and the written is dead. With regard to the word 'score', he holds that 'a score is a series of dead marks. But scoring is also an action, making it inherently alive. ' ${ }^{99}$ However, the deconstructive aspect inherent in Nickel's scores is not overlooked by the composer: 'The term living scores evokes a paradox. Musical scores are an attempt to fix things down. Living is unfixable. ${ }^{90}$ A living score in this oral form, then, is a contradiction, defying the categorical boundary that Nickel himself buys into. It implicates the notion of the score in a far more transient and less fixed form than the ideology of the work concept. ${ }^{91}$

His living scores also undermine the hierarchical relationship and categorical division between composer and performer. Drawing on the work of Éliane Radigue, the living scores foster a collaborative aspect, where the composer is not simply transmitting, but engaged in an exchange which leads to a composition. Nickel describes Radigue as fostering an 'equality between composer and performer'. ${ }^{92}$ This highlights the ever-present aspect of dialogue in the interactions of composer, notation and performer as well as the fact that, "The piece [...] is imagined as being represented in the score but, insofar as it exists at all, is in fact constructed by thinking about what might lie behind remembered or (currently) conceivable performances. ${ }^{93}$

This puts aside the dichotomy between the performance as living and the score as dead, and rather embraces the idea of the living score. All performance is based on some

\footnotetext{
86 Gayatri Chakravorty Spivak, 'Translator's Preface', in Derrida, Of Grammatology, ix-xl (p. xiv).

87 Plato, Phaedrus, trans. Christopher Rowe (London: Penguin, 2005), 64.

88 Luke Nickel, 'Living Scores: A Portfolio of Orally-Transmitted Experimental Music Compositions' (Ph.D. dissertation, Bath Spa University, 2017), 2.3.4 (emphasis original).

89 Ibid., 2.3 .0 (emphasis original).

90 Ibid.

91 Cf. Lydia Goehr, The Imaginary Museum of Musical Works: An Essay in the Philosophy of Music (Oxford: Clarendon Press, 1992).

92 Luke Nickel, 'Occam Notions: Collaboration and the Performer's Perspective in Éliane Radigue's Occam Ocean', Tempo, 70 (2016), 22-35 (p. 33).

93 Leech-Wilkinson, 'Compositions, Scores, Performances, Meanings', 4.1.
} 
element of memory - that is, of prepared material - and some form of live interpretation, for even a performer who subscribes to the idealized authority of the composer responds in some way to the moment of performance, even if only by accident. Nickel, by his purely oral score, implicitly deconstructs, exactly analogously to Derrida, the notion of the score being dead and the performance living, blurring the two into a 'living score'.

These acts deconstruct the notion of the work as a definite object. To come back to Barron's argument on the relationship of the law to music, she writes:

The law's inability to comprehend the idea of musical production as a 'continuing process' has important practical effects: some lose, and others gain, from the copyright system's propensity to identify musical entities in terms of finished and inviolable works; and moreover these losses and gains tend to consolidate already existing relations of social inequality..$^{94}$

These examples of ephemeral notation are direct deconstructions of the assumptions about what constitutes the object of intellectual property. This is at the very least an invitation to consider how transcribers' acts of notation fit into these ideas from an ethical, if not a scholarly, concern with these structures.

\section{Transcription and perception}

The general category of 'descriptive notation' is one which is certainly not untroubled as a concept. As discussed above, Ellingson does go some way towards critiquing the dichotomy between prescriptive and descriptive notation, drawing attention to the uses of conceptual notation. However, the nature of descriptive notation itself remains somewhat ambiguous. For example, it is pertinent to ask: 'Who is the description by, and why did they create it?', or, 'If the transcriber has to listen to a recording repeatedly to create a transcription, how can this be representative of the experience of a listener in the moment?' In short, 'Where is the perceptual basis for the claim to being descriptive?'

One example of a composer whose notation is interwoven with these questions is Andrew Hugill. In 2009, Hugill was diagnosed with Ménière's disease, which has resulted in severe hearing loss and diplacusis. Diplacusis results in the altering of pitches heard, and in Hugill's case, this means hearing roughly the right pitch in one ear and another pitch in the other. ${ }^{95}$ As a result, he struggled with how to continue composing:

If I continue to create normal music, I will have to revert to writing dots on paper because I can no longer hear digital sound accurately enough. At least my aural imagination is intact. If, on the other hand, I want my music to reflect my own experiences, then I have to start engaging with my aural limitations by introducing into my sound world those elements that I actually hear (including such disturbing things as diplacusis and tinnitus). How to do this yet still create beautiful music is a real challenge. ${ }^{96}$

94 Barron, 'Introduction: Harmony or Dissonance?', 33.

95 Andrew Hugill, 'Aural Diversity' (2018), <https://andrewhugill.com/writings/Aural_Diversity. html> (accessed 26 July 2021).

96

Ibid. 
Stemming from this is his exploration of aural diversity - the idea that everyone hears differently - and his actively questioning the assumptions of the kind of musicological thinking that descriptive transcription buys into:

Most music is made and reproduced on the assumption that all listeners hear in the same way. Psychologists generally write about aural perception as though it is a single standardised thing. Acousticians normally design the sonic environment using uniform measures. Musicologists typically discuss music as it is meant to be heard, not as it actually is heard. ${ }^{97}$

Through Hugill's compositional exploration of his hearing he has created a 'diplacusis piano' which simulates his experience of listening to the piano for those with more normal hearing. He has been actively inclined towards deconstructing the idealized hearing of the music implicitly involved in musical analysis of all sorts, including that of descriptive notation. Rather than the notation depicting 'the note' in its normative form, Hugill's notation refers to his actual experience of the note. Just as Ferneyhough undermines assumptions about the composer-performer-audience relationship and McLaughlin does the same for the relationship between performer and instrument, so Hugill's project undermines the assumptions about the relationship between the instrument/performer and the listener.

Hugill does not simply write and talk about this: notation is a key element of his implicit critique of the assumed transparency of this relationship. In composing for and with the diplacusis piano, Hugill came up against the problem that what he hears, he hears with his own diplacusis in addition. The key to this problem, he found, was to compose using spectrograms of each note (see Figures 5 and 6, which are stills taken from videos of moving spectrograms). By seeing the note, he learnt the sonic character of each one and composed not in spite of the diplacusis but using the particularities of his hearing to create something that embraced the character of the sound as his material. Hugill began to see each note as a composition in itself with a development of partials and beats that became his material (as is highlighted in the visualization in Figure 5). ${ }^{98}$ In one method of composing in this way, Hugill looks for features of the spectrum which complement or lead on to one another and chains them together (as illustrated in Figure 6). ${ }^{99}$ In a certain sense, the note stops being conceived as a single pitch (as in Western staff notation) and becomes an interplay of partials, highlighted as being contingent on the individual's hearing. In the videos from which Figures 5 and 6 are taken, the right-hand side represents the present moment and the spectrogram moves left until it disappears off the other side. The depth refers to the frequency of the partials and the height is the amplitude. In using spectrogram notation based on his hearing, Hugill highlights the normativity and potential deficiencies of a musicology that is based on an 'ideal' hearing rather than the actual experience of hearing music with any individual aural idiosyncrasies.

\footnotetext{
97 Ibid. (emphasis original).

98 Andrew Hugill, 'Thirty Minutes', conference paper, Aural Diversity, University of Leicester, 2019.

99 Personal communication, 6 March 2020.
} 


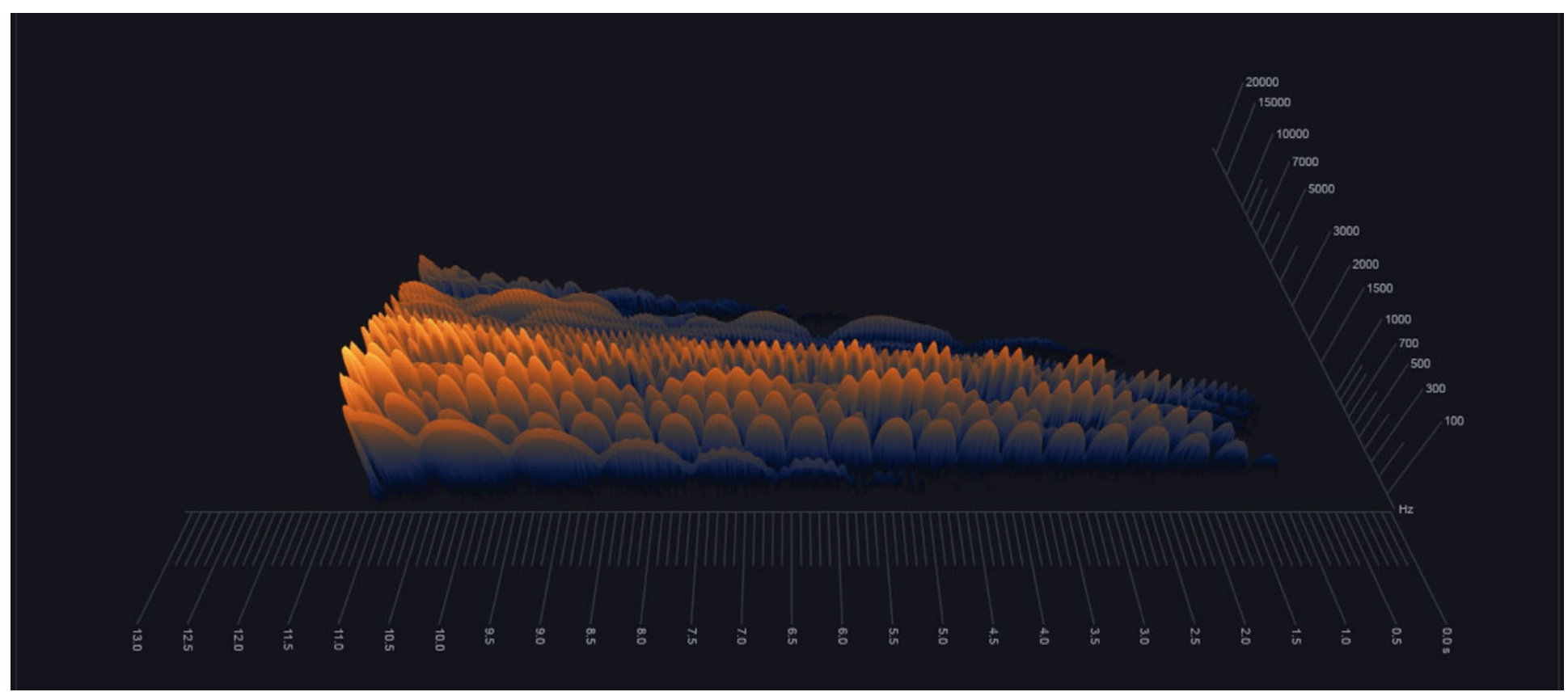

Figure 5 Extract from Andrew Hugill, Improvisation \#2. ( 2019 Andrew Hugill, reproduced by permission of the composer. 


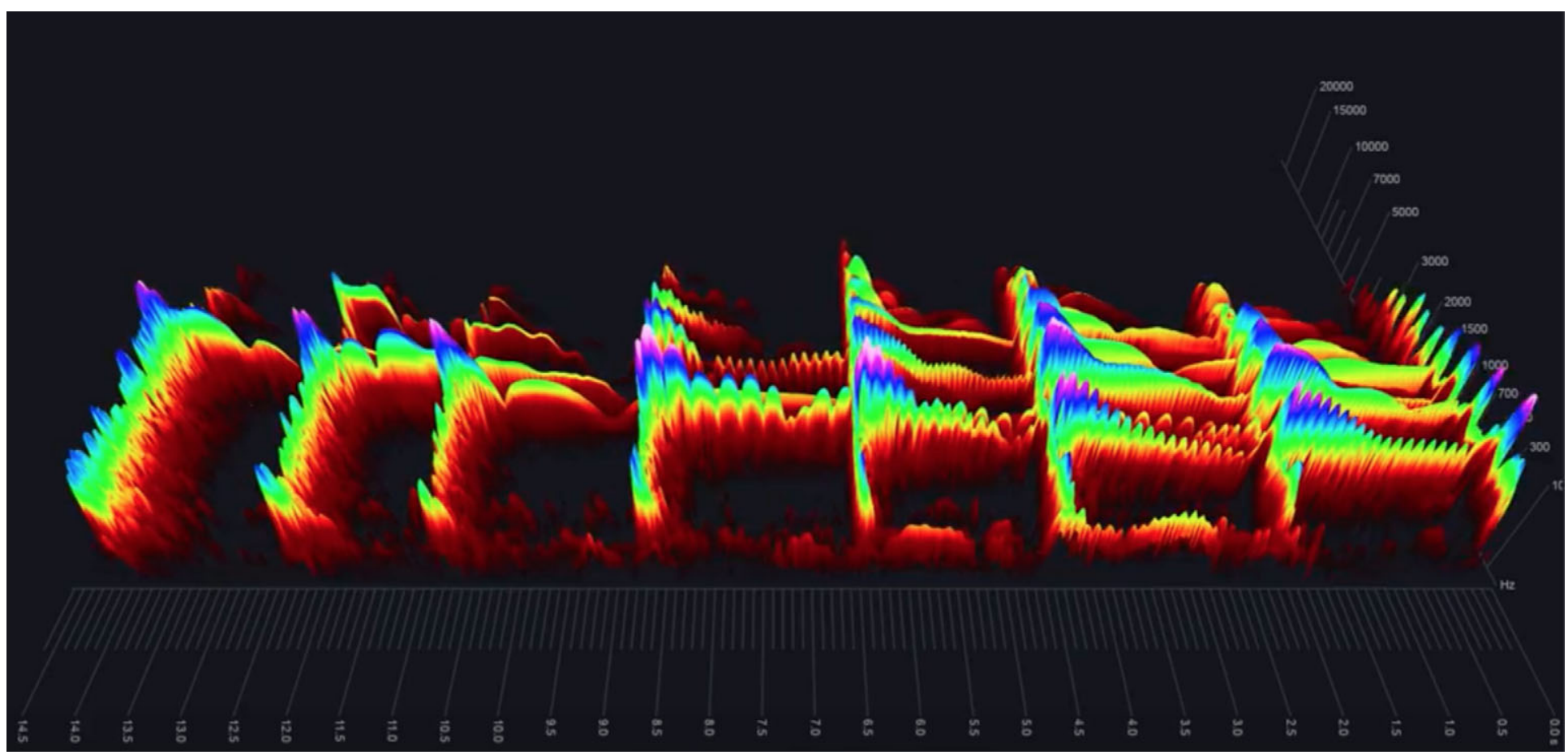

Figure 6 Extract from Andrew Hugill, Improvisation \#7. (C) 2019 Andrew Hugill, reproduced by permission of the composer. 

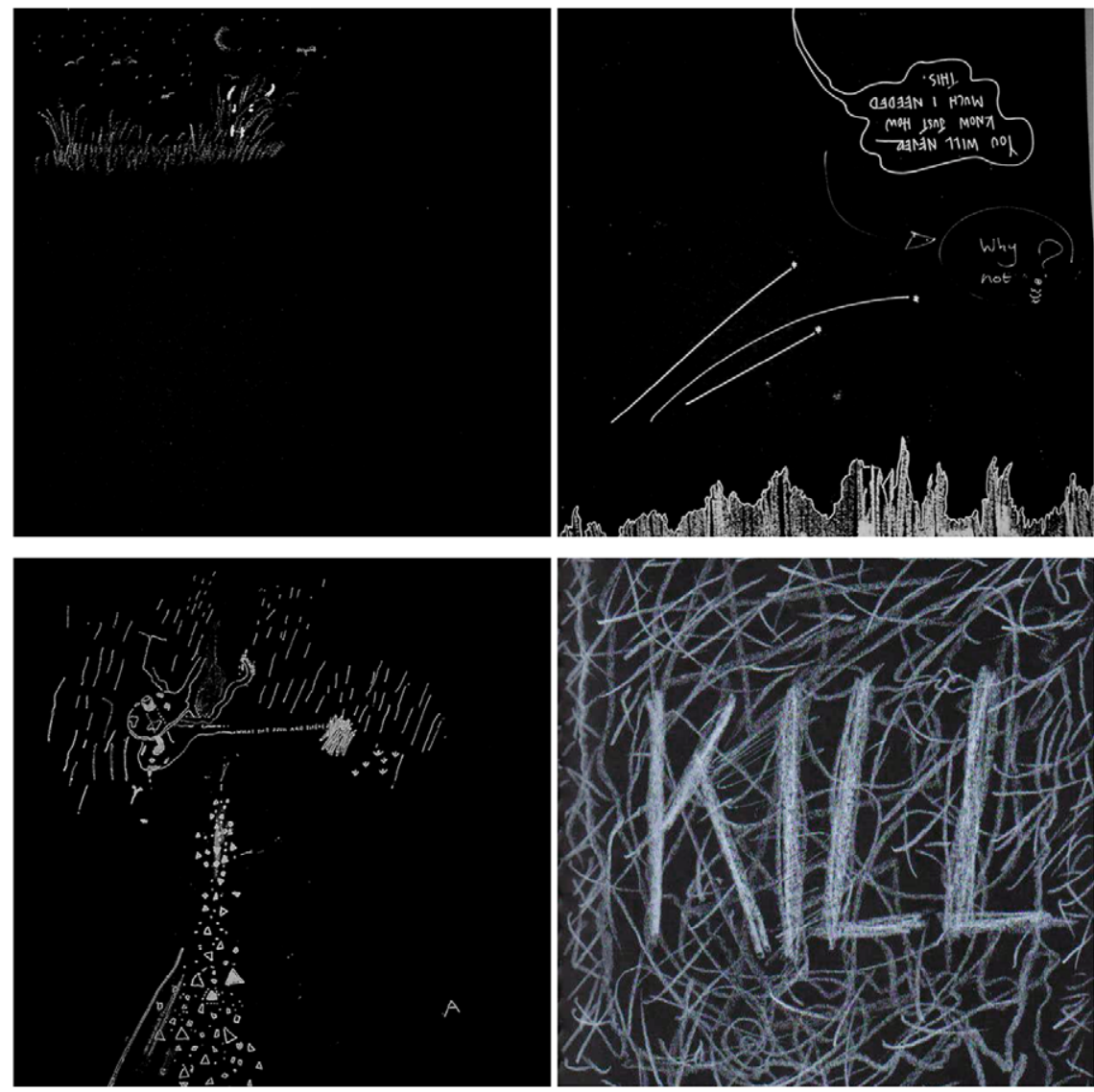

Figure 7 Audience transcriptions responding to the audiovisual installation as part of Guy Harries's Shadowgraphs. (C) 2009 Guy Harries, reproduced by permission of the composer.

The idea of notation as descriptive - as describing the experience of the music - is more generally deconstructed in the work of Guy Harries. He does this through acts of notation by audience-participants in an installation which is part of a larger work called Shadowgraphs. In this work, Harries invites the visitor 'to enter a small, secluded room with a CD player on a small table and, hanging on the walls, an array of enigmatic snapshots taken in the woods [...] The visitor is instructed to sit down, listen to the soundtrack and draw in a black sketchbook. ${ }^{\prime} 00$ The visitor, observing the photos and hearing the soundtrack, is prompted to draw, and the graphic results vary considerably, from seemingly free association with the materials to linear, time-based notations and direct reaction to others' drawings (see Figure 7). I see no reason not to call these drawings a descriptive transcription. Harries himself refers to them as 'a reverse graphic score', ${ }^{101}$ helping the audience to process and engage with the music. This is what

\footnotetext{
${ }^{100}$ Guy Harries, “The Open Work”: Ecologies of Participation', Organised Sound, 18 (2013), 3-13 (p. 9).

${ }^{101}$ Personal communication, 9 January 2020.
} 
transcription does in all circumstances. Creating a visual representation of the music whether it is intended to allow the transcriber and reader to engage with the music more actively or to perform complex analyses - serves as an aid to processing and understanding the notator's experience of the music. The perceptual diversity displayed in these drawings further undermines the assumption of the transparent relationship between sound and perception.

However, further to this, these transcriptions critique this individual subjectivist position - the idea that each participant has an experience of their own. Ethnomusicology is hardly a stranger to the collective creation of cultural perceptions, but in this situation Harries takes the element of communal meaning generation and amplifies it through the notational process, exploring 'the relationship between the individual experience and the way it is shared with others'. ${ }^{102}$ The audience's transcriptions are not simply individualistic representations, with participants presenting their reflections on the experience (as in the idealized case of scholarship), but their work instead becomes part of the artwork, remaining in the book in the installation for others to experience when they come to add their own contribution.

As discussed above, the critique of the categories of descriptive notation has featured prominently in the history of ethnomusicology. However, if there is a value in conceptual transcription, perhaps there is also value in transcriptions that pertain to the phenomenology of listening to music - a perceptual transcription. Hugill's and Harries's examples invite a consideration of the role of subjectivity in description. This is not to say that it has not been considered before; a classic illustration of transcriptional subjectivity was the 1964 Society for Ethnomusicology symposium's comparison of four transcriptions of the same song, accompanied by mouth bow. ${ }^{103}$ However, Hugill's and Harries's acts of notation - and, importantly, the processes that created them - might help to deconstruct the ready-to-hand concept of descriptive notation, asking: Where is the aural diversity? Where is the diversity in reactions? Where is the co-creation of meaning?

The definiteness of the category of descriptive transcription is questioned, too, in Miller's circular scores (see again Figure 2). In their creation and subsequent lives as agential objects, they undermine the dichotomy commonly set up between prescriptive and descriptive notations. The score is descriptive in the sense that it represents the music with no intention of it being an instructive tool for performance. However, this definition was shown to be a porous one when serendipity led Miller to have several of her scores performed both as the piece on which the score was based (involving prior knowledge of the original Western staff notation) and as free interpretation. The scores are transcribed from the staff notation but are informed by recordings; they describe the patterns of repetition, but have been used as source material for performance. In a Derridian way, then, the prescriptive is within the descriptive and vice versa, and so Miller's notation deconstructs the prescriptive/descriptive dichotomy by showing that these objects disconnect from intention and enter a world in which they may act independently of their creator's original concept.

102 Harries, “The Open Work”, 12.

103 England et al., 'Symposium on Transcription and Analysis'. 


\section{Closing remarks/opening questions}

I have argued here that notational systems inherently structure the way that music is understood by the notator and by those who read the notation, and that these structures, while necessary, can be kept in check by the use of deconstructive notations. However, it may well seem to the reader that I have strayed from my subject in some of the above examples. I have claimed to be presenting a set of notations that deconstruct approaches and assumptions about notation, and it might reasonably be asked, for instance, whether my example of McLaughlin's work is about the composition rather than the notation. After all, if there were no notation at all, then the same deconstructive aspect would be present in the 'work'. And could the same not be said of the example of Saunders's work? In this view, notation is a representation of the composition. How, then, can it be said that McLaughlin and Saunders present deconstructive notations, when their scores themselves seem to be - in their format at least - simply text pieces, the likes of which the Fluxus group, Pauline Oliveros, Karlheinz Stockhausen, Cardew and others have created many times in the past? Further, McLaughlin himself says that he would, in many ways, prefer not to notate at all; he would rather use a more collaborative, in-person approach instead. ${ }^{104}$ However, to continue in the deconstructionist vein, I contend that one must examine this line between composition/musical event (the pure, good, living, internal entity, existing in its purest form in the world of ideas) and notation (the distorting, bad, dead, external entity, which is only a shadow on the wall of Plato's cave). Plato dreams of memory without a sign, says Derrida; ${ }^{105}$ is the dream here of composition without notation? For Derrida, the text extends beyond the conventional boundary:

The text overruns all the limits assigned to it so far $[\ldots]$ - all the limits, everything that was to be set up in opposition to writing (speech, life, the world, the real, history, and what not. Every field of reference - to body or mind, conscious or unconscious, politics, economics, and so forth). ${ }^{106}$

If scores can be living, oral and evolving, as in Nickel's work, then what is to stop collaboration being a kind of notation - a text? If material objects have agency, isn't any interaction between score and performer two-way - as seen at its extreme in Baldwin's work - and therefore collaborative? The boundary between a composition and a work of notation does not hold up when one strays off the beaten track of notational convention, and this is precisely why these examples are deconstructive. Here, these examples support this, not allowing scholarship 'to master, to dominate by inserting its definition into simple, clear-cut oppositions: good and evil, inside and outside, true and false, essence and appearance'. ${ }^{107}$ They push this to the point where the dichotomy

\footnotetext{
${ }_{104}$ McLaughlin, 'intra-play'.

105 Derrida, Dissemination, 109.

106 Jacques Derrida, 'Living On', Deconstruction and Criticism, ed. Harold Bloom, Paul de Man, Jacques Derrida, Geoffrey H. Hartman and J. Hillis Miller (London: Routledge \& Kegan Paul, 1979), 75-176 (p. 84).

107 Derrida, Dissemination, 103.
} 
between notation and composition - aligned, as I have presented it here, with Plato's writing and speech - dissolves. For the transcriber, then, the boundaries between notation and musical event begin to fade. This is not in the sense that the notation becomes identical to the musical event, but that it stops being supplementary to the music and becomes part of the text. So, in the very undermining of the structures of notation which has been explored here is found the empowerment of notation to become more than a supplement to musical action.

This is just one way in which the structures of notation can be conceptually transgressed through encounters with deconstructive notation. For a transcriber (or other notator) in such an encounter, the play of ambiguity concealed within the structure of conventional notations begins to emerge. Those elements which are systematically ignored or reduced to a single normative point (whether it be a single note, a single standard of aural perception, a single choice of many possibilities, etc.) are made visible and the categorical definitions made porous.

Each of the examples I have presented questions in its own way the assumptions that common notational practices maintain. In light of this, it is hard not to feel a stress as some disciplinary tenets fall away. Indeed, Derrida is clear that this is part of the deconstructive process, as centred structure is based on certainty, with which 'anxiety can be mastered, for anxiety is invariably the result of a certain mode of being implicated in the game, of being caught in the game, of being as it were at stake in the game'. ${ }^{108}$ It is, therefore, expected that ethnomusicology will look for some system to come along and allay its uncertainties, but it is this very uncertainty that is crucial to its practice. I am not calling for an abandonment of notation, nor even the scuppering of the idea of a global notation such as that proposed by Killick. Definition is a necessary endeavour - no one can live in an uncategorized world, and so transcription, too, must use certain categories for particular ends. However, it should also be realized that, ultimately, definition leads either to tautology or to travesty; in defining a category, one cannot help but either define it meaninglessly as 'whatever it is' or exclude things which should be included.

Deconstruction is, then, a kind of housekeeping, a check on definitional domination, and what I argue is that the quest to deconstruct that which is constructed should never be abandoned. Scholars necessarily pursue dissonance in the course of their work and should not see the maintenance of this dissonance as problematic but should to some degree accept the mantle of being experts in ignorance.

The question of how best to operate deconstruction is only in part answered here. I do not have a single method to present. In fact, as the subtitle of this section suggests, the line of thinking pursued here is intended to open up questions rather than to settle them, even to the extent of not providing closure on how exactly to go about this. It is clear from Derrida's work, however, that a good place to start is in play; it is hard not to see his description of Theuth as at least partially a reflection on this method of play, and perhaps on Derrida himself:

${ }_{108}$ Derrida, Writing and Difference, 352. 
[Theuth] cannot be assigned a fixed spot in the play of differences. Sly, slippery, and masked, an intriguer and a card, like Hermes, he is neither king nor jack, but rather a sort of joker, a floating signifier, a wild card, one who puts play into play. ${ }^{109}$

Miller, in my conversation with her on her circular scores, explained that she began developing the notation through her exploration of the medium of etching rather than as part of a musical endeavour. She told me that had she been asked at the beginning what she was doing, she would not have had a defined objective; instead, she was exploring the materiality of the etching process. Her intention in this was not focused on analysis or dissemination of music, but rather engaged with her keen interest in music, allowing the playful encounter between music and the materiality of printmaking. This is what I mean by play here - making time to let go of well-trodden paths and clear goals and stepping into intellectual free-fall just to see where one lands.

Whether notation is simple or complex, altering its framework can change the graphical lens through which the musical act is seen. To give a practical suggestion, a transcriber could start for instance by reassigning categories to the graphical parameters; just changing the horizontal axis from representing time to representing distance would be an example of this. If this were done in a socially stratified place, this could create a socio-acoustic transcription, illustrating the change in experienced sound according to the social stratification. Like Hugill's Aural Diversity project, this would question the 'ideal' hearing of music, showing the diversity in perception depending on the social (and therefore physical) position of the listener. Again, this is not a prescription for a system, but an invitation to open up the vast array of possibilities for different notational lenses, which might allow ethnomusicologists to see and present their subjects differently by questioning the assumptions built into any notational system.

As I have said, Derrida always opens more questions than he closes - he is always a provocateur and rarely a peacemaker. And yet (in a very Derridian way) in the noise of this unrest, a kind of peace can be glimpsed; an unruly peace that throws the institutions of convention off balance - for it is the tranquillity of these institutions when undisturbed that fosters an unquestioned and silent violence. So let us imagine Theuth now approaching the god-king with a brand new artifice - a system of musical notation. And then, rather than asking, 'Is it good or evil?', as Derrida does, let's play.

${ }^{109}$ Derrida, Dissemination, 93 (emphasis original). 